\title{
Subclavian Vein Stenosis
}

National Cancer Institute

\section{Source}

National Cancer Institute. Subclavian Vein Stenosis. NCI Thesaurus. Code C114850.

Narrowing of the lumen of the subclavian vein. 